\title{
Alfred De Musset, Fantasio
}

\section{Valentina Ponzetto}

\section{(2) OpenEdition}

\section{Journals}

\section{Edizione digitale}

URL: https://journals.openedition.org/studifrancesi/39667

DOI: 10.4000/studifrancesi.39667

ISSN: 2427-5856

\section{Editore}

Rosenberg \& Sellier

\section{Edizione cartacea}

Data di pubblicazione: 1 décembre 2004

Paginazione: 397-398

ISSN: 0039-2944

\section{Notizia bibliografica digitale}

Valentina Ponzetto, «Alfred De Musset, Fantasio», Studi Francesi [Online], 143 (XLVIII | II) | 2004, online dal 30 novembre 2015, consultato il 19 mai 2021. URL: http://journals.openedition.org/studifrancesi/ 39667 ; DOI: https://doi.org/10.4000/studifrancesi.39667

Questo documento è stato generato automaticamente il 19 mai 2021.

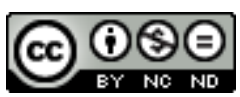

Studi Francesi è distribuita con Licenza Creative Commons Attribuzione - Non commerciale - Non opere derivate 4.0 Internazionale. 


\title{
Alfred De Musset, Fantasio
}

\author{
Valentina Ponzetto
}

\section{NOTIZIA}

ALFRED DE MUSSET, Fantasio, édition présentée, établie et annotée par FRANK LESTRINGANT, Paris, Gallimard, 2003 («Foliothéâtre»), pp. 191.

1 Difficile da definire -una fantasia hoffmanniana? un intermezzo teatrale? una féerie da Bibliothèque bleue?- e ancor più difficile da mettere in scena per l'esiguità dell'azione $\mathrm{e}$ l'estensione sproporzionata dell'autopresentazione del protagonista, quasi un monologo dalle infinite divagazioni, Fantasio è spesso considerato come una curiosità romantica adatta tutt'al più alla lettura, e per giunta ad una lettura accademica. L'introduzione a questa nuova edizione curata da Frank Lestringant per Gallimard ha invece il merito di offrirne una chiave di lettura estremamente moderna e una ragione di interesse prettamente teatrale, presentando la pièce come una sorta di illusion comique, una riflessione metateatrale sui generi e gli stili proponibili nello scrivere per la scena. Fantasio come un attualissimo laboratorio di teatro sperimentale, dunque, che si interroga senza sosta sulla propria natura, trasformando tali interrogativi in elementi drammaturgici, o incarnandoli in una dialettica fra i personaggi.

2 Secondo la felice intuizione del critico, infatti, ogni personaggio della pièce rappresenta uno stile, o meglio la tentazione da parte di Musset di aderire a quello stile, e al tempo stesso la sua caricatura. Così la principessa Elsbeth, pronta a sacrificarsi sposando, per ragion di Stato, il ridicolo principe di Mantova, è una moderna eroina di tragedia, e la sua declamazione un po' forzata, sebbene commovente, una presa in giro dei classicisti e delle loro velleità di resuscitare lo stile tragico. In un ironico accostamento di generi, al linguaggio tragico di Elsbeth rispondono il vocabolario della devozione popolare o del romanzo d'appendice della Governante, sua confidente, che incarna il romanzesco à l'eau de rose e le sue trasposizioni sceniche, e la bonomia del re di Baviera, suo padre, rappresentante del dramma borghese o della comédie larmoyante alla Diderot e alla Beaumarchais. Quanto al principe di Mantova, che si traveste da aiutante di campo, fa 
la sua corte declamando luoghi comuni in stile schilleriano o hugoliano, ed è, sebbene per interposta persona, vittima del furto della parrucca per mezzo di un amo in cima ad un filo, si può riconoscere in lui la caricatura vivente del dramma romantico, inverosimile, eccessivamente solenne, dalla retorica esagerata e dai macchinosi artifici scenici.

3 Fantasio, l'ironia personificata, commenta con un certo distacco questo gioco delle parti. Romantico per temperamento, classicista per provocazione, egli risponde alla definizione di «romantique né classique» che era stata forgiata per lo stesso Musset. In questo atteggiamento, più che nella malinconia o nel fuoco di fila di battute, egli si fa portavoce e alter-ego dell'autore, e in tale chiave autobiografica il critico legge il riferimento esplicito a Boileau e Pope, modelli classici di genere parodico. La derisione del romanticismo non è però che la cifra del più profondo spirito romantico. L'eroe ironico, romantico rinnegato, approda alla conclusione che ogni tipo di azione è impossibile, anche, o forse prima di tutto, in campo artistico.

4 In Fantasio travestito da buffone disilluso Lestringant vede dunque la concretizzazione dell'impossibilità per Musset di scrivere per il teatro e di farsi rappresentare, e, più in generale, l'autoritratto dell'intera generazione perduta dei figli del secolo, per cui ironia e follia sono l'unica reazione possibile al senso di impotenza. Il critico recupera così, rivedendolo secondo criteri più moderni, il vecchio tema autobiografico, che, come mostra anche l'historique de la mise en scène riportata in appendice, è stato per lungo tempo e un po' superficialmente privilegiato. Fantasio appare dunque come un ritratto fantasiosamente trasposto non del solo Musset, ma di tutta una generazione in crisi, crisi di cui Lestringant sottolinea soprattutto la componente politica, legandola all'attualità del tempo e ai contemporanei Lorenzaccio e La Confession d'un enfant du siècle. 